\title{
Ağrı Balık Gölü Balıkçılığının Genel Durumu
}

\author{
Adem Sezai BOZAOĞLU \\ Van Yüzüncü Yll Üniversitesi Su Ürünleri Fakültesi, Van, Türkiye
}

Öz: Bu çalışma Balık Gölü’nde balıkçılığın genel durumunun belirlenebilmesi için TemmuzEkim 2019 tarihleri arasında, 28 balıkçı ile yüz yüze anket görüşmesi yapılarak gerçekleştirilmiştir. 0,4 donam faktörü ile donatılmış 140,150 ve $160 \mathrm{~mm}$ ağ göZ açıklığına sahip multifilament fanyalı uzatma ağları ile 0,4 donam faktörü ile donatılmış 80 ve $100 \mathrm{~mm}$ ağ göz açıklığına sahip monofilament sade uzatma ağlarının kullanıldığı saptanmıştır. Bu ağları kullanan teknelerin ortalama yaşı $11,14 \pm 5,03$ y1l, ortalama boyu $5,54 \pm 0,34 \mathrm{~m}$, ortalama motor yaş1

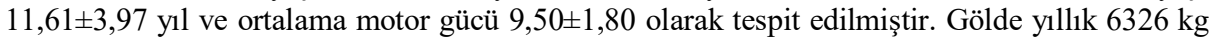
balık avlandığı belirlenmiştir. Teknelerde ortalama $1,10 \pm 0,31$ tayfanın sürekli olarak, pay karşılığında çalıştı̆̆ı saptanmıştır. Balıkçıların \%68'inin ilkokul, \%18'inin ortaokul ve \%14'ünün lise mezunu olduğu tespit edilmiştir. Balıkçıların ortalama yaşının $36,03 \pm 8,16$ olduğu, \%93'ünün

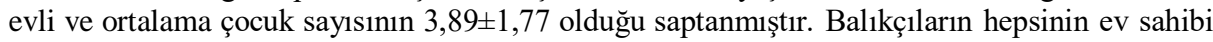

*Sorumlu yazarın: Adem Sezai BOZAOĞLU

Van Yüzüncü Y1l Üniversitesi Su Ürünleri

Fakültesi, Van, Türkiye.

凶: sbozaoglu@ hotmail.com

Cep telefonu : +90 (533) 6532345 olduğu belirlenmiştir. Hiçbirinin sağlı sigortasının olmadığı, bunun yerine hepsinin yeşil kartının olduğu tespit edilmiştir. Ankete katılan balıkçıların \%59'u çocuklarının bu işi yapmasını istemediğini belirtmişlerdir. Ayrıca tamamının balıkçılığı bırakmayı düşünmedikleri tespit edilmiştir. Araştırma sonucuna göre balıkçıların hepsinin ikinci bir işinin olduğu belirlenmiştir. Çoğunluğunun inşaatta işçi olarak çalıştığı, bunun yanında hayvancılık ile de uğraştıkları saptanmıştır.

Anahtar kelimeler: Balıkçılık, fanyalı uzatma ağı, sade uzatma ağı, sosyo-ekonomik yapı.

\section{General Status of Lake Ağrı Balık Fishery}

*Corresponding author's: Adem Sezai BOZAOĞLU

Van Yuzuncu Y1l University, Faculty of Fisheries, Van, Turkey.

凶: sbozaoglu@ hotmail.com

Mobile telephone : +90 (533) 6532345

\begin{abstract}
This study was carried out by conducting face to face interviews with 28 fishermen between July and October 2019 to identify general situation of fisheries in Lake Balık. It was found out that there were trammel nets with mesh sizes of 140,150 and $160 \mathrm{~mm}$ equipped with hanging ratio of 0.4 . Furthermore, gillnets with mesh sizes of 80 and $100 \mathrm{~mm}$ equipped with hanging ratio of 0.4 were also observed. The average age of the boats using these trammel and gillnet was $11.14 \pm 5.03$ years, while the average length was $5.54 \pm 0.34 \mathrm{~m}$. On the other hand, the average engine age was $11.61 \pm 3.97$ years, and the average engine power was $9.50 \pm 1.80$. It was revealed that $6326 \mathrm{~kg}$ of fish were caught annually in the lake. In terms of the economical situation of the crew, it was found out that $1.10 \pm 0.31$ of the crew were working continuously for share on average. According to the answers related to educational background, it was noted down that $68 \%$ of fishermen were primary school, $18 \%$ were middle school and $14 \%$ were high school graduates. For marital status and family structures, it was observed that the average age of fishermen was $36.03 \pm 8.16$, and $93 \%$ of them were married. The average number of children was $3.89 \pm 1.77$. Also, all of the fishermen were houseowners. Questions related to health insurance issue highlighted that none of the fishermen had health insurance, but all of them had green cards which are given by the government for people who are low in budget. 59\% of the fishermen in the survey stated that they did not want their children to become fishermen in the future, while all of the fishermen in the study did not consider stopping fishing. According to the results of the research, it was determined that all the fishermen had a second job. It has been determined that most of them work as construction workers, as well as animal husbandry.
\end{abstract}

Keywords: Fisheries, gill net, trammel net, socio-economic structure. 


\section{GíRíş}

Ağrı Balık Gölü Ağrı il sınırlarında yer alan bölgenin en önemli balıkçılık sahalarının başında yer almaktadır. Gölde yerli tür olarak sazan (Cyprinus carpio) (Linnaeus, 1758), doğal alabalık (Salmo trutta) (Linnaeus, 1758) ve siraz (Capoeta capoeta) (Guldenstaedt, 1772) olmak üzere 2 familyaya ait 3 tür bulunmaktadır (Öztürk, 2014). Ağrı Balık Gölü'nün yüzeyi, yüksek rakımı nedeniyle, Ocak ve Mayıs ayları arasında tamamen buzla kaplanmaktadır. Haziran ayından itibaren göl yüzeyindeki buzların erimesiyle balıkçılık faaliyetlerinin başladığı gölde, yılın 7 ayı balıkçılık yapılmaktadır. Ülkemizde 2019 yılında iç sulardan avcılık yolu ile 31596 ton balık elde edilmiş olup 3999 ton ile bu rakamın yaklaşık \% 10'luk bölümünü sazan, siraz ve doğal alabalık oluşturmaktadır (TÜİK, 2020). Bu türler aynı zamanda Ağrı Balık Gölü’ndeki hedef türleri oluşmaktadır. $\mathrm{Bu}$ türlerin avcılığında sadece multifilament fanyalı ve monofilament sade uzatma ağları kullanılmaktadır. 2020 yılı verilerine göre Türkiye iç sularında 2831 adet balıkçı teknesi vardır (TÜİK, 2020). Yapılan arazi çalışması sonucunda Balık Gölü’nde 28 teknenin avcılık yaptığı tespit edilmiştir.

Karmaşık ve dinamik bir yapıya sahip olan balıkçılık yönetiminin temel amacı balık stoklarının sürdürülebilir kullanımını sağlamaktır. $\mathrm{Bu}$ bağlamda sürdürülebilirlik, bir balıkçının kaynağın üretim kapasitesini engellemeden devamlı o kaynaktan faydalanması anlamına gelir (Kolding \& van Zwieten, 2014). Balıkçılık yönetiminin başarısı temelde, büyük ölçüde sağlıklı veri toplanması ve bunların doğru metotlarla işlenmesine bağlıdır (Ünal, 2003). $\mathrm{Bu}$ verilerin önemli bir bölümünü biyolojik veriler, av araç gereçleriyle ilgili veriler, demografik ve sosyo-ekonomik veriler oluşturmaktadır (Mutlu vd., 2018a; Mutlu vd., 2018b). Bir bölgedeki balıkçılık yapan kişi ve balıkçı tekne sayısı, av araçları çeşitliliği ve kapasitesi, avlanan türler ve av miktarları, gerekli ve önemlidir. Bu tür verilerin sürekli alınması ve izlenmesi gerekir (Tokaç vd., 2007). Balıkçılığın sürdürülebilirliğin sağlanması için sadece ekolojik ve biyolojik verilerin toplanması yeterli olmayabilir. Bunun yanında sosyo-ekonomik verilerin toplanmasına da ihtiyaç vardır. Özellikle küçük ölçekli balıkçılığın yapıldığı iç sularda bu verilerin toplanması daha da önemlidir. $\mathrm{Bu}$ bağlamda Türkiye'de iç sularda balıkçılık yapılan alanlarda balıkçılığın sosyo-ekonomik yapısı ile ilgili birçok çalışma mevcuttur (Avan, 2007; Ergüden vd., 2007; Dartay vd., 2009; Doğan, 2009; Yiğit vd., 2009; Özer vd., 2010; Uzmanoğlu \& Soylu, 2012; Demirol \& Yüksel, 2013; Uzmanoğlu vd., 2013; Mete \& Yüksel, 2014; Korkut vd., 2015; Dartay \& Canpolat, 2017; Akkuş \& Bozaoğlu, 2019; Bozaoğlu \& Akkuş, 2019; Bozaoğlu \& Yeşil, 2019; Yılmaz \& Pulatsü, 2019; Reis vd., 2020). Bu araştırma, Ağrı Balık Gölü balıkçılarının sosyo-ekonomik analizi üzerine yapılmış ilk çalışmadır. Sosyo-ekonomik açıdan büyük öneme sahip küçük ölçekli balıkçılığın sürdürülebilirliğinin sağlanması için etkin ve doğru yönetim politikalarına ihtiyaç vardır (Karakuş, 2015). Bu çalışmada, Balık Gölü balıkçılığının sosyo-ekonomik yapısı, kullanılan av araçları ile balıkçı teknelerinin özellikleri, gölde avlanan balık miktarının belirlenmesi amaçlanmıştır.

\section{MATERYAL VE METOT}

Çalışma Fırat Havzası'nın önemli balıkçılık sahalarından biri olan Balık Gölü’nde yürütülmüştür (Şekil 1). Doğubayazıt ilçe merkezinin kuzeybatı uç noktasında yer alan Balık Gölü, Doğubayazıt ilçe merkezine $54 \mathrm{~km}$, Taşlıçay ilçe merkezine ise $27 \mathrm{~km}$ uzaklıkta bulunmaktadır. Yüksek dağ sıraları arasındaki bir çöküntü alanı içerisinde kuzey-güney doğrultusunda uzanan $34 \mathrm{~km}^{2}$ yüzey alanına sahip ve deniz seviyesinden 2241 metre yükseklikte yer alan Balık Gölü tipik bir lav seti gölüdür. Balık Gölü deniz seviyesinden $2241 \mathrm{~m}$ yükseklikte yer alması nedeniyle, Türkiye'nin en yüksekte yer alan doğal gölü olma özelliğini taşır. Gölün şekli düzensiz olup kenar çizgileri oldukça girinti ve çıkıntılıdır (Karabulut, 2018). Çalışma kapsamında, Temmuz-Ekim 2019 tarihleri arasında, Balık Gölü'nde aktif olarak çalışan 28 tekne sahibi ile yüz yüze anket görüşmesi yapılmıştır. Çalışmada Özbilgin vd., 2009 tarafından hazırlanan anket kullanılmıştır. Anket çalışmasında gölde avlanan balık miktarı, avcılık yapılan gün sayısı, tayfaların sayısı ve çalışma durumları, balıkçıların eğitim durumları, medeni durumları, barınma durumu, balıkçılığa nasıl başladıkları, bu işi bırakmayı düşünüp düşünmedikleri, sosyal güvence durumları, çocuklarının bu işi yapmalarını isteyip istemedikleri ve bu işten başka bir iş yapıp yapmadıkları sorularına cevap aranmıştır. Ayrıca, gölde kullanılan fanyalı ve sade uzatma ağlarının teknik özellikleri, avcılık operasyon bilgileri ile bu ağları kullanan teknelerin özellikleri yerinde incelenmiştir. Kullanılan ağın teknik özellikleri FAO standartlarına göre çizilmiştir. Ağların teknik özelliklerinin çiziminde "Corel Draw 12" programı kullanılmıştır.

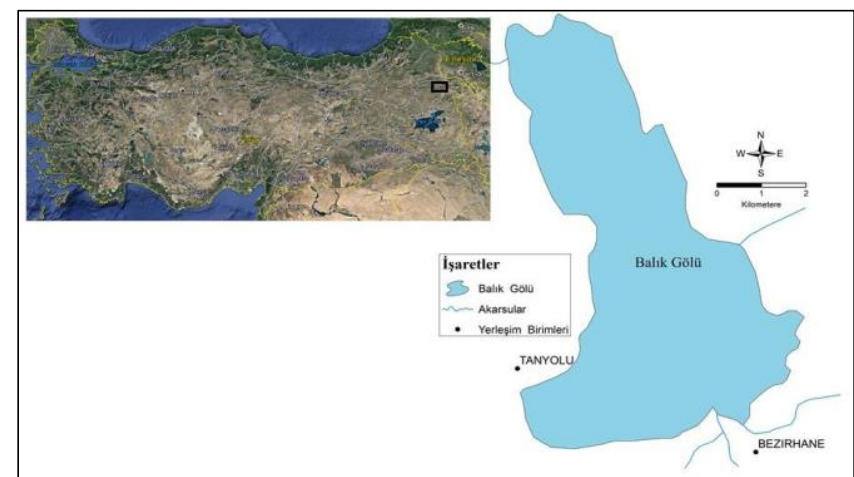

Şekil 1. Araştırma alanı.

Figure 1. Research area. 


\section{BULGULAR}

Balık Gölü’nde iki farklı uzatma ağı kullanıldığı tespit edilmiştir. Sazan ve siraz balıklarının avcılığı için multifilament fanyalı uzatma ağları, alabalık avcılığı için ise sade monofilament uzatma ağlarının kullanıldı̆̆ belirlenmiştir.

Fanyalı Multifilament Uzatma Ăğının Teknik Özellikleri: Balık Gölü’nde kullanılan fanyalı uzatma ağları 0,4 donam faktörü ile donatılmıştır. Torlar; 210 denye 3 numara ip kalınlığında, Poliamid (PA), 140, 150 ve 160 mm tam göz boyunda ve ağın derinliği 60 gözden oluşmaktadır. Fanyalar ise; 210 denye 9 numara ip kalınlığında, PA, 450 tam göz boyunda ve 5 göz derinliğindedir. Mantar yakada 80 $\mathrm{m}$ uzunluğunda Polipropilen (PP) $5 \mathrm{~mm}$ çaplı ana halat ile 69-79 adet arasında plastik (Pl) 3 numara siyah renkli yüzdürücü kullanılmaktadır. Kurşun yakada ise; $82 \mathrm{~m}$ uzunluğunda Polipropilen (PP) $5 \mathrm{~mm}$ çaplı ana halat ve PP 4 mm çaplı koşma halatı ile 104-119 adet arasında 50 gr'lık kurşun $(\mathrm{Pb})$ kullanılmaktadır. $\mathrm{Bu}$ uzatma ağları mantar yakaya \%40, kurşun yakaya ise \%41 donam faktörü ile donatılmıştır (Şekil 2,3,4).

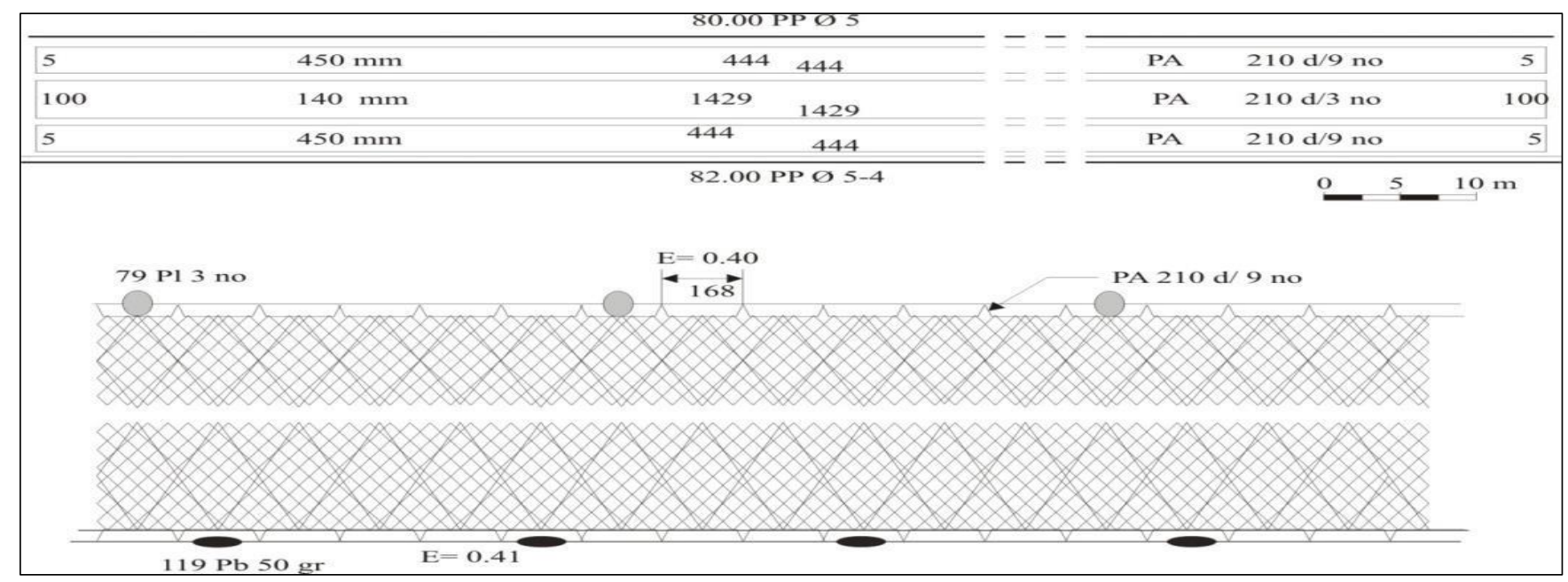

Sekil 2. Sazan avcılığında kullanılan $140 \mathrm{~mm}$ ağ göz açıklığına sahip fanyalı uzatma ağının teknik planı.

Figure 2. Technical plan of mesh size of $140 \mathrm{~mm}$ trammel net used for carp.

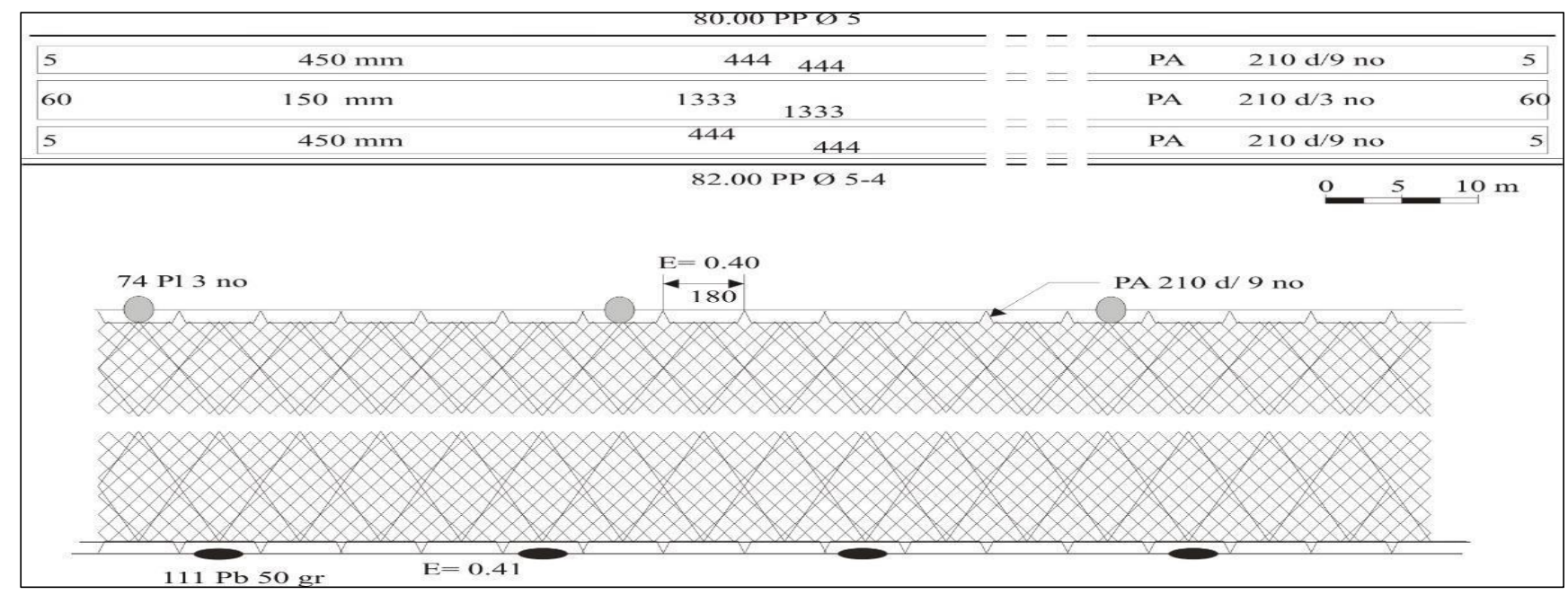

Şekil 3. Sazan avcılığında kullanılan $150 \mathrm{~mm}$ ağ göz açıklığına sahip fanyalı uzatma ağının teknik planı.

Figure 3. Technical plan of mesh size of $150 \mathrm{~mm}$ trammel net used for carp.

Sade Monofilament Uzatma Ă̆ının Teknik Özellikleri: Monofilament poliamid yapıda olan sade uzatma ağların tor göz genişliği 40-50 mm, yüksekliğine göz sayısı 100 göz, ağiplik kalınlığı ise 0,20 mm'dir. Her bir posta uzunluğu $80 \mathrm{~m}$ olan bu ağlarda, mantar ve kurşun yakalarda 5 numara kalınlığındaki PP halatların tek sıra olarak kullanıldığı, büyüklüğü 3 numara olan mantarlar ve
50 gr olan kurşunlar ile donatıldığı belirlenmiştir (Şekil $5,6)$.

Balıkçı Teknelerinin Özellikleri: Balık Gölü'ndeki tekneler sacdan yapılmış olup, ortalama yaşı $11,14 \pm 3$ yıl, ortalama boyu $5,54 \pm 4 \mathrm{~m}$, ortalama motor yaşı $11,61 \pm 7$ y1l ve ortalama motor gücü $9,50 \pm 1$ BG olarak tespit edilmiştir. 
Aylara Göre Avlanan Balık Miktarı: Balık Gölü'nde yapılan anket sonuçlarına göre 28 teknenin yıllık $6326 \mathrm{~kg}$ balık avladığı tespit edilmiştir. Avlanan balıkların yaklaşık \% 95'ini sazan oluşturmaktadır. Toplam avda en yüksek avcılık miktarı Ağustos’ta $1669 \pm 13,23$ kg, en düşük avcılık miktarı ise $656 \pm 4,25 \quad \mathrm{~kg}$ ile Kasım'da gerçekleşmiştir. Diğer aylarda ise sırasıyla Temmuz'da $1239 \pm 6,22 \mathrm{~kg}$, Haziran'da $1188 \pm 7,26 \mathrm{~kg}$, Eylül'de $812 \pm 5,01 \mathrm{~kg}$ ve Ekim'de $762 \pm 3,28 \mathrm{~kg}$ balık avlandığ saptanmıştır (Şekil 7).

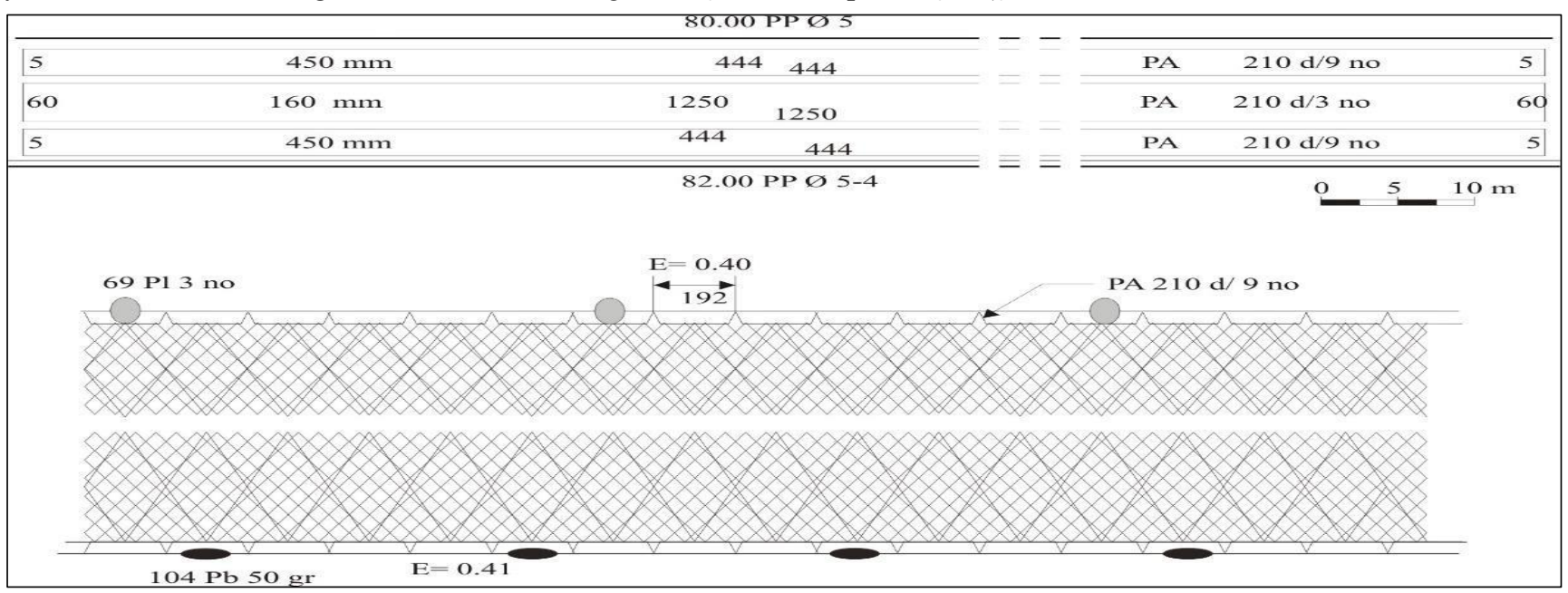

Şekil 4. Sazan avcılığında kullanılan $160 \mathrm{~mm}$ ağ göz açıklığına sahip fanyalı uzatma ağının teknik planı.

Figure 4. Technical plan of mesh size of $160 \mathrm{~mm}$ trammel net used for carp.

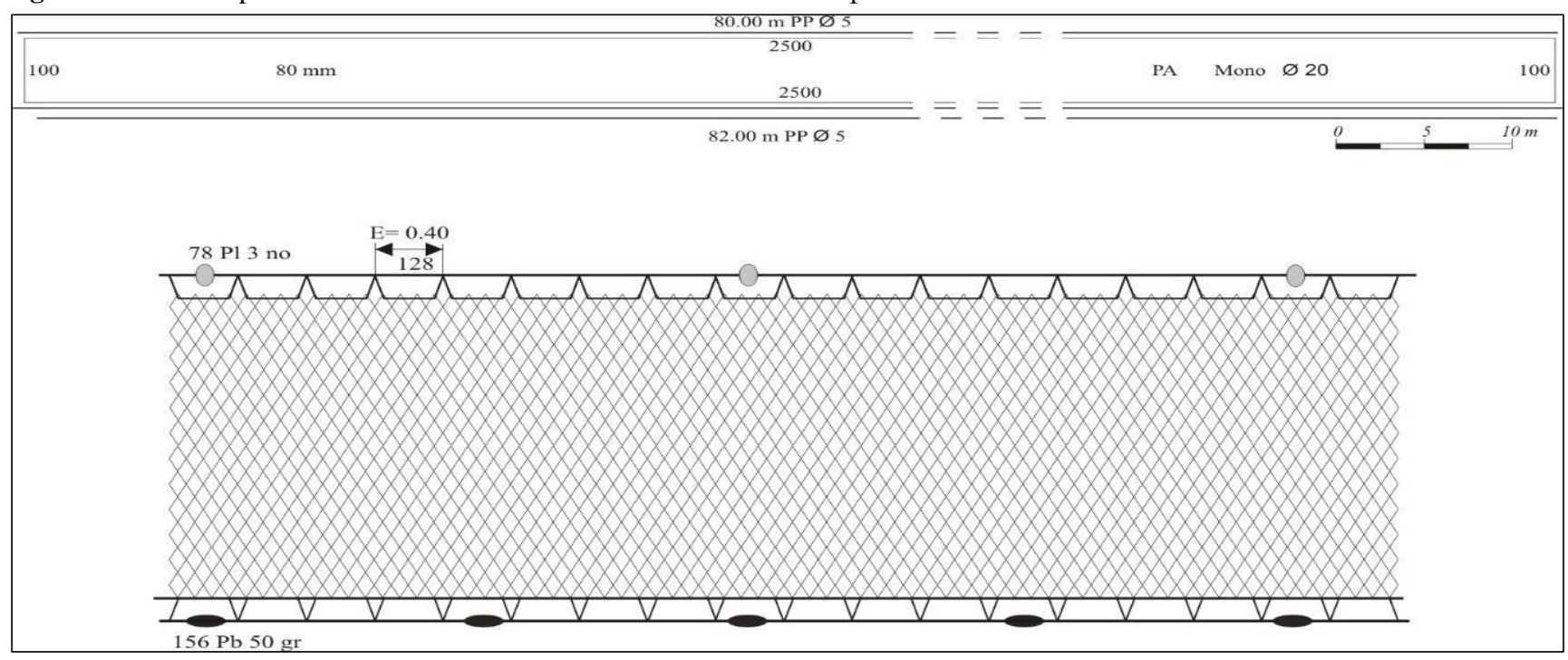

Şekil 5. Alabalık avcılığında kullanılan $80 \mathrm{~mm}$ ağ göz açıklığına sahip sade monofilament uzatma ağının teknik planı.

Figure 5. Technical plan of mesh size of $80 \mathrm{~mm}$ monofilament gill net used for trout.

Avcılık Yapılan Ortalama Gün Sayısı: Balıkçıların avcılığa çıktıkları ortalama gün sayısı incelendiğinde, en fazla avcılı̆̆a $14,83 \pm 2,15$ gün ile Ağustos'ta, en az avcılığa ise 11,72 $\pm 1,62$ gün ile Kasım ayında çıktıkları saptanmıştır. Diğer avcılığa çıktıkları ortalama gün sayısı ise sirası ile Temmuz'da 14,38 $\pm 2,35$

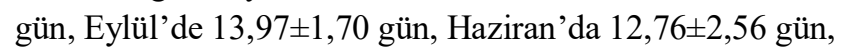

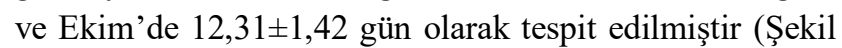
$8)$.

Avcılık Operasyon Bilgileri: Balıkçılarla yapılan anket sonuçlarına göre, ağların ortalama 24 saat suda kaldığı tespit edilmiştir. Genellikle sabah saat 7:00 de atılan ağların ertesi sabah saat 7:00 de kaldırıldığı belirlenmiştir. Balıkçıların ağlarını 1-8 kulaç arasındaki derinliklere bıraktıkları belirlenmiştir. Balıkçı teknelerin hiçbirinde ağ tamburu olmadığı için ağların el ile atılıp toplandığ edilmiştir.

Balıkçıların Sosyo-Ekonomik Yapısı: Balık Gölü'nde teknelerde çalışan tayfaların ortalama sayısı $1,10 \pm 0,31$ olarak tespit edilmiştir. Tayfaların hepsinin sürekli ve pay karşılığı çalıştığı tespit edilmiştir. Balık Gölü'nde balıkçıların \%68'inin ilkokul, \%18'inin ortaokul ve \%14'ünün lise mezunu olduğu saptanmıştır. (Şekil 9). 


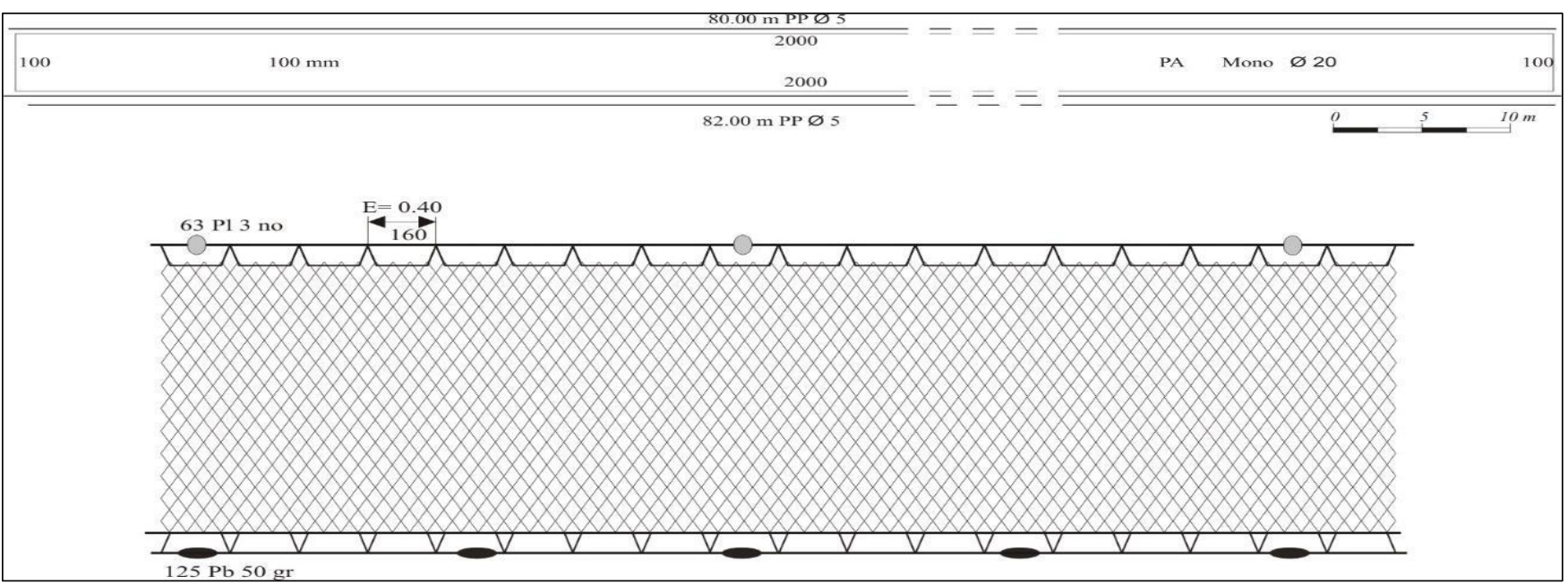

Şekil 6. Alabalık avcılığında kullanılan $100 \mathrm{~mm}$ ağ göz açıklığına sahip sade monofilament uzatma ağının teknik planı.

Figure 6. Technical plan of mesh size of $100 \mathrm{~mm}$ monofilament gill net used for trout.

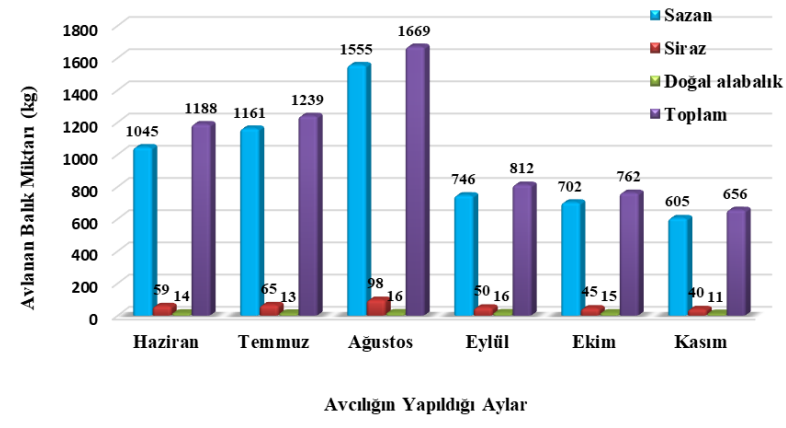

Şekil 7. Balık Gölü'nde aylara göre avlanan balık miktarı (kg). Figure 7. The amount of fish monthly caught in the Lake Balık.

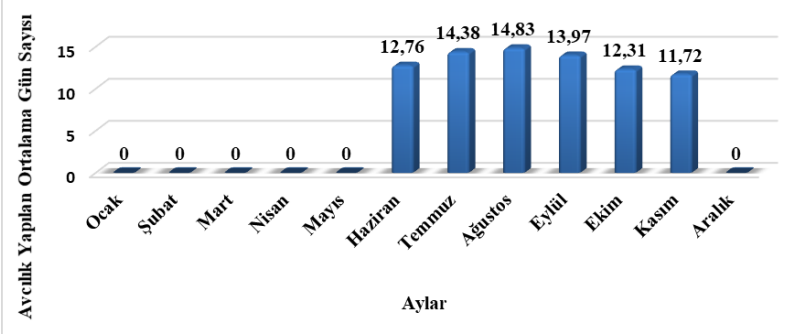

Şekil 8. Avcılık yapılan ortalama gün sayısı.

Figure 8. Average number of days of catching.

Çalışmada, Balık Gölü’nde balıkçılık yapanların ortalama yaşının 36,03 $\pm 8,16$ olduğu, \%93’ünün evli ve

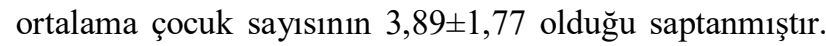
Balıkçıların tamamının ev sahibi olduğu tespit edilmiştir.

\section{SONUÇ VE TARTIŞMA}

Balık Gölü'nde yerli tür olarak sazan, doğal alabalık ve siraz olmak üzere 2 familyaya ait 3 tür bulunmakta ve avcılığı yapılmaktadır. Ayrıca gölde, göle
Balıkçıların hiçbirinin sağlık sigortasının olmadığı, bunun yerine hepsinin yeşil kartının olduğu saptanmıştır. Balıkçıların büyük bir kesimi balıkçılığın devlet tarafindan yeteri kadar desteklenmediğini beyan etmişlerdir. Balıkçılardan hiçbirinin balıkçılık kredisi kullanmadığı tespit edilmiştir. Tüm balıç̧ılar ürünlerini kendilerinin sattığını beyan etmişılerdir. Ankete katılan balıkçıların \%59'unun çocuklarının bu işi meslek olarak yapmasını istemediğini belirtmişlerdir. Ayrıca, balıkçıların tamamının balıkçılığı bırakmayı düşünmedikleri tespit edilmiştir. Araştırma sonucuna göre balıkçıların hepsinin ikinci bir işinin olduğu belirlenmiştir. Çoğunluğunun inşaatta işçi olarak çalıştığı, bunun yanında hayvancılık ile de uğraştıkları saptanmıştır. Balıkçıların karşılaştıkları en önemli sorun ise bilinçsiz ve aşırı avcılık olduğu tespit edilmiştir.

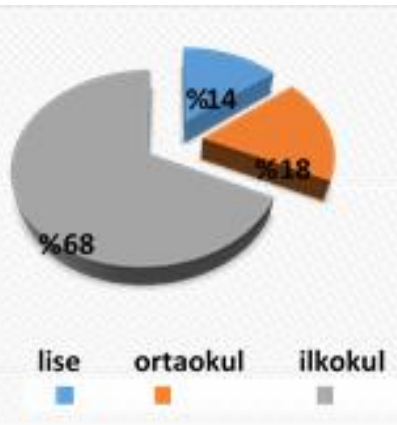

Şekil 9. Balıkçıların eğitim durumları.

Figure 9. Education status of fishermen.

nasıl aşılandığı belli olmayan tatlı su kereviti (Astacus leptodactylus Eschscholtz, 1823) bulunmaktadır. Geçmiş y1llarda doğal alabalık, sazan ve siraz üzerine yoğunlaşan balıkçılık, gölde doğal alabalığın yok olma noktasına gelmesi nedeniyle son yillarda sazan ve siraz üzerinde 
yoğunlaşmıştır. Bu nedenle doğal alabalık avcılığ 1 yıllık yaklaşık olarak $85 \mathrm{~kg}$ a kadar düşmüştür. Çalışmadaki anket sonuçlarına göre, gölde 2019 yilında toplam $6326 \mathrm{~kg}$ balık avlandığı tespit edilmiştir. İç sularda yapılan diğer araştırmalarda, Nazik Gölü’nde 2019 yılında yaklaşık 55316 kg (Bozaoğlu \& Akkuş, 2019), Ulubat Gölü'nde 2006 yılında 642500 kg (Çınar, 2010), Atatürk Baraj Gölü Bozova Bölgesi'nde Şubat 1998-Nisan 1999 tarihleri arasında $44670 \mathrm{~kg}$ (Duman \& Çelik, 2001), Demirköprü Baraj Gölü'nde 2008 - 2015 yılları arasında $21292 \mathrm{~kg}$ sazan avlandığı bildirilmiştir (Şen, 2016). Balık Gölü’nde yıllık avlanan balık miktarının diğer çalışmalar ile karşılaştırıldığında düşük olduğu görülmektedir. Bölgenin iklim şartlarından dolayı gölde sadece yılın 7 ayı avcılık yapılabiliyor. Ayrıca, gölde yaşayan tür sayısının az ve sınırlı olması, iklim ve habitat özellikleri ile gölün balık verimliliğinin düşük olması da, yakalanan balık miktarının düşük olmasının diğer nedenleri olarak sıralanabilir.

Balık Gölü’nde sazan avcıllı̆̆ için 140,150 ve $160 \mathrm{~mm}$ ağ göz açıklığına sahip multifilament fanyalı uzatma ağları kullanırken, alabalık avcılığında ise 80 ve100 $\mathrm{mm}$ ağ göz açıklığına sahip sade monofilament uzatma ağlarının kullanıldığı belirlenmiştir. Yeni Karpuzlu (İpsala-Edirne) Baraj Gölü’nde göz genişliği 32-125 mm arasında değişen fanyalı uzatma ağları kullanıldığı bildirilmiştir (Uzmanoğlu \& Soylu, 2012). Eğirdir Gölü'nde Aralık 2009-Nisan 2010 tarihleri arasında yapılan bir çalışmada 100, 110, 120 ve $130 \mathrm{~mm}$ göz genişliğinde fanyalı uzatma ağlarının kullanıldığı bildirilmiştir (Çınar, 2010). Eğirdir Gölü’nde 2014 yılında sazan avcılığında $100,110,120,130$ ve $140 \mathrm{~mm}$ göz açıklı̆̆ında fanyalı ağlar kullanılmıştır (Cilbiz vd., 2014). Demirköprü Baraj Gölü’nde ticari balıkçıların sazan avcıllığında 130, 140, 150, $160 \mathrm{~mm}$ göz genişliğinde multifilament uzatma ağlarını kullandıkları belirlenmiștir (Şen, 2016). Manyas Gölü’nde 2015 yılında sazan avcılığında 100, 110, 120, 130 ve $140 \mathrm{~mm}$ göz açıklığında fanyalı ağlar kullanılmıștır (Cilbiz vd., 2015). Demirköprü Baraj Gölü’nde 2108 yılında yapılan bir çalışmada sazan avcıllı̆ı̆ında 130, 140, 150 ve $160 \mathrm{~mm}$ ağ göz açılı̆ğında multifilament ağların kullanıldığı bildirilmiştir (Dereli vd., 2018). Karakaya Baraj Gölü’nde gökkuşağı alabalığ 1 avcılığında $40 \mathrm{~mm}$ göz genişliğine sahip 0,18-0,23 mm materyal ip kalınlığına sahip monofilament sade uzatma ağ 1 kullanıldığ belirlenmiştir (Ateşşahin vd., 2011). Kainji Gölü'nde 2014 yılında yapılan bir çalışmada alabalık avcılığında $12,16,5$, $18,5,21,5,25,30,35,40,50$ ve $60 \mathrm{~mm}$ ağ göz genişlikleri test edilmiştir (Yem, 2014). Balık Gölü'nde sazan ve alabalık avcılığı için kullanılan ağların ağ göz açıklıkları ile diğer çalışmalardaki ağ göz açıklıkları arasında benzer sonuçlar tespit edilmesinin yanında, Balık Gölü'nde kullanılan a ̆ göz açıklıklarının daha sınırlı olduğu da belirlenmiştir. Balık Gölü’nde tür çeşitliliğinin az olması nedeniyle avcılık yalnızca üç tür, sazan, siraz ve alabalık üzerinde yapılmaktadır. Fakat, diğer göller tür zenginliği bakımından Balık Gölü’nden daha zengindir. Yukarıdaki çalışmalarda kullanılan ağlar, Astacus leptadactylus Esc., 1823 (Kerevit), Carassius sp. (C1bır), Cyprinus carpio Lin., 1758 (Sazan), Esox lucius Lin., 1758 (Turna), Sander lucioperca Lin., 1758 (Sudak balığı), Perca fluviatilis Lin., 1758 (Tatlısu levreği)) gibi büyüklük olarak farklı türlerin avcılığında kullanılmaktadır. Balık Gölü’ne göre tür çeşitliliği bakımından zengin olan göllerde ağ göz genişliğinin farklı olması beklenen bir durumdur. Teknede çalışan ortalama tayfa sayısı $1,10 \pm 0,31$ olarak tespit edilmiştir. Yakın bölgelerde yapılan benzer çalışmalarda, Bitlis ilinde bulunan, Nazik Gölü’nde bu sayı 1,22 $\pm 0,73$ (Bozaoğlu \& Akkuş, 2019), Van Gölü'nde ise 2,34 $\pm 0,77$ olarak bulunmuştur (Bozaoğlu \& Yeşil, 2019). Balık Gölü'nde teknede çalışan ortalama tayfa sayısı Nazik Gölü ile benzer olmasına karşın Van Gölü'ne göre daha düşük olduğu görülmektedir. Van Gölü 3712 km² yüzey alanı ile ülkemizin en büyük gölü olup göldeki tekne boyları ortalama 12,4 $\pm 2,44$ 'tür. Nazik Gölü'nde tekne boyu

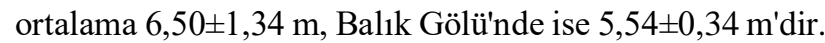
Tekne boyu büyüdükçe ihtiyaç duyulan tayfa sayısı artacağından dolayı çalışmada elde edilen ortalama tayfa sayısının Nazik Gölü ile benzer, Van Gölü'nden düşük çıkması beklenen bir durumdur. Balıkçıların sosyoekonomik yapıları incelendiğinde, Balık Gölü'nde avcılık yapan balıkçıların ortalama yaşının $36,03 \pm 8,16$ olduğu tespit edilmiştir. Nazik Gölü'nde yapılan bir çalışmada, balıkçıların ortalama yaşının 36,44 $\pm 10,04$ (Bozaoğlu \& Akkuş, 2019). Van Gölü'nde yapılan bir çalışmada ise ortalama balıkçı yaşının 40,14 $\pm 11,37$ olduğu saptanmıștır (Bozaoğlu \& Yeşil 2019). Çalışmalardan elde edilen verilere bakıldığında çalışmalar arasında benzer sonuçlar tespit edilmiştir. Bu benzerliğin en önemli nedeninin avlak sahalarının birbirine yakın olmasından dolayı balıcçıların benzer bölgesel kültüre sahip olmasından kaynaklandığını düşünmekteyiz. İç sularda yapılan diğer çalışmalarda balıkçı yaş aralıklarının Eğirdir, Marmara ve Demirköprü Baraj Gölleri'nde 46-65, (Yılmaz \& Pulatsü, 2019). Keban Baraj Gölü’nde 40-52 (Dartay vd., 2010), Ulubat ve Poyrazlar Göllerinde 40-49, (Özer vd., 2010; Yiğit vd., 2009). Seyhan Baraj Gölü’nde 21-65, (Ergüden vd., 2007; Mete \& Yüksel, 2014), Beyşehir Gölü’nde 21-59, (Korkut vd., 2015), Seyhan Baraj Gölünde 26 ile 59 (Ergüden vd., 2007), Manyas Gölü'nde 26 ile 72 (Avan, 2007) olarak tespit etmişlerdir. Çalışmalar arasındaki yaş farklılıklarının bölgesel değişikliklerden kaynaklandığı düşünülmektedir. Balık Gölü balıkçılarının eğitim durumu incelendiğinde $\% 68$ 'inin ilkokul \%18'inin ortaokul ve \%14'ünün lise mezunu olduğu saptanmıştır. Yapılan benzer çalışmalarda ise Nazik Gölü balıkçılarının \%78'inin ilkokul mezunu olduğu saptanmıştır (Bozaoğlu \& Akkuş, 2019). Van 
Gölü'nde 2019 yılında yapılan çalışmada balıkçıların 62'sinin ilkokul, \%23'ünün ortaokul, \% 13'ünün lise ve sadece \%2'sinin üniversite mezunu olduğu saptanmıştır (Bozaoğlu \& Yeşil, 2019). 2011 yılında Ege Bölgesi’ndeki balıkçıların \%54,2'sinin ilkokul mezunu olduğunu bildirmiştir (Doğan \& Gönülal, 2011). Tekirdağ ilindeki balıkçıların \%64,2'sinin ilkokul, \%22,2'sinin ortaokul, $\% 13,1$ 'inin lise eğitimine sahip oldukları belirtilmiştir (Güngör vd., 2007). Bu çalışmalarda tespit edilen eğitim durumları ile çalışmamızda saptanan eğitim durumları arasında benzerlik tespit edilmiştir. Bunun yanında İstanbul ili küçük ölçekli balıkçıların eğitim düzeyleri ise $\% 2,4$ 'ünün okuma yazma bilmediği, \%3,6'sının okuryazar, \%40,1'inin ilkokul, \%17,4'ünün ortaokul, $\% 26,3$ 'ünün lise ve \%10,2'sinin üniversite mezunu olduğu bildirilmiştir (Doğan, 2009). Hatay (Samandağ) ilinde yapılan çalışmada balıkçıların \%7'sinin ilkokul, \%53'ünün ortaokul, \%26'sının lise ve \%14'ünün ise yüksekokulüniversite mezunu olduğunu bildirmişlerdir (Şahinler vd., 2005). Çalışmalar ile bu çalışmada tespit edilen eğitim durumları arasında farklılık tespit edilmiştir. Farklılıkların en önemli nedeninin bölgesel farklılıklardan kaynaklandığ 1 düşünülmektedir. Sosyal güvence durumları incelendiğinde, balıkçıların hiçbirinin sağlık sigortasının olmadığı, bunun yerine hepsinin yeşil kartının olduğu saptanmıştır. Nazik Gölü’ndeki balıkçıların \%85'inin sağlık sigortasının olmadığı bildirilmiştir (Bozaoğlu \& Akkuş, 2019). Keban Baraj Gölü Pertek Bölgesi balıkçılarının yarısından fazlasının, \%61,29'unun sosyal güvencesinin olmadığ rapor edilmiş̧ir (Dartay vd., 2009). $\mathrm{Bu}$ çalışmalarda tespit edilen sosyal güvenlik durumları ile çalışmamızda saptanan sosyal güvenlik durumları arasında nispeten benzerlik tespit edilmiștir. Bunun en önemli nedeninin bölgelerin yakın olmasından kaynaklandığ düşünülmektedir. Bunun yanında Gökçeada balıkçılarının $\% 62$ 'sinin sosyal güvencesinin olduğu bildirilmiștir (Doğan \& Gönülal, 2011). Orta Karadeniz Bölgesi balıkçılarının \%56'sının sosyal güvencesinin olduğu belirtilmiştir (Yücel, 2006). Akdeniz Bölgesi sahil şeridi deniz balıkçılarının \%72'sinin sosyal sağlık kuruluşlarına üye oldukları belirtilmiştir (Sağlam \& Karadal, 2016). Bu çalışmalarda tespit edilen sosyal güvenlik durumları ile çalışmamızda saptanan sosyal güvenlik durumları arasında farklılık tespit edilmiştir. Bunun en önemli nedeninin ise bölgelerin uzak olması ve farklı bir sosyal yaşantıya sahip olmasından kaynaklandığını düşünmekteyiz. Balıkçıların barınma durumları incelendiğinde Balık Gölü balıkçılarının tamamımın ev sahibi olduğu saptanmıştır. Van Gölü’nde yapılan bir çalışmada balıkçıların ev sahibi olma oranının \%70 olduğu bildirilmektedir (Bozaoğlu \& Yeşil, 2019). Nazik Gölü’ndeki balıkçıların, \%95'inin ev sahibi olduğu tespit edilmiştir (Bozaoğlu \& Akkuş, 2019). İskenderun Bölgesi balıkçılarının \%72'sinin ev sahibi olduğu belirtilmiştir. Karadeniz Bölgesi kıyı balıkçılarına baktığımızda Artvin \%90, Rize \%89, Trabzon \%40, Giresun \%78, Ordu \%72, Samsun \%50, Sinop \%75 oranında ev sahibi oldukları rapor edilmiştir. Akdeniz bölgesi kıyı balıkçılı̆̆ı için yapılan çalışmaya göre; Hatay ve Adana'daki balıkçıların \%60'ının, Mersin'dekilerin $\% 50$ 'sinin, Antalya'dakilerin \%69'unun ev sahibi olduğu belirtilirken, kalan kısmın kiracı olarak barındığı bildirilmiştir (Karadal, 2014). Balık Gölü’nde çalışan balıkçıların büyük bir kısmının ikinci bir iş olarak inşaat, çiftçilik ve hayvancılıkla uğraştıkları tespit edilmiş̧ir. Ev sahiplik oranın yüksek olmasının önemli bir sebebinin de bu olduğu kanaatindeyiz. Balıkçıların \%93'ünün evli

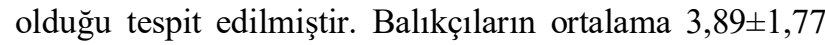
çocuğa sahip oldukları saptanmıştır. Yakın bölgelerde yapılan çalışmalarda da benzer sonuçlar tespit edilmiştir (Bozaoğlu \& Yeşil, 2019; Bozaoğlu \& Akkuş, 2019). Bu benzerliğin sebebi, bölgedeki örf ve adetlerden dolayı, erken yaşta evlenmeden kaynaklanmaktadır. Balık Gölü’nde balıkçılarla yapılan yüz yüze anket sonuçlarına göre, balıkçıların en önemli sorunlarının bilinçsiz ve aşırı avcılık olduğu tespit edilmiştir. Bazı balıkçıların yasak dönemde avcılık yaptıkları ve fazla miktarda ağ kullanıldığı için balıkçıların çoğunun bu durumdan memnun olmadıkları belirlenmiştir. Balıkçıların hiçbirinin balıkçılığı bırakmak istemedikleri tespit edilmiştir. Bunun yanında \%59'u çocuklarının bu işi yapmalarını istemedikleri belirlenmiştir. Buradan da açıça görülmektedir ki Balık Gölü balıkçıları balıkçılığın geleceğini iyi görmemektedirler. Bu nedenle, Balık Gölü balık kaynaklarının yönetilmesinde sürdürülebilir bir balıkçılık politikasının izlenmesinin yanında balıkçının da varlığını sürdürebilmesi için etkin ve doğru yönetim uygulamalarına ihtiyaç vardır. Balık Gölü'nde balık stoklarının korunması ve sürdürülebilir bir balıkçılık için ekolojik ve biyolojik verilerin yanında sosyo-ekonomik verilerin de izlenmesi ve sürekli olarak yenilenmesi gerekmektedir.

\section{KAYNAKLAR}

Akkuş, M. \& Bozaoğlu, A.S. (2019). Van Gölü Havzasındaki amatör balıkçılığın sosyo ekonomik analizi. Journal of Anatolian Environmental and Animal Sciences, 4(3), 506-512. DOI: 10.35229/jaes.605597

Ateşşahin, T., Dartay, M., Duman, E. \& Gül, M.R. (2011). Karakaya Baraj Gölü'nde gökkuşağı alabalığı (Oncorhynchus mykiss, Walbaum 1792) avcıllğı ve av verimi. Biyoloji Bilimleri Araştırma Dergisi, 4(1), 113-117.

Avan, S. (2007). Manyas Gölü balıkçılarının sosyoekonomik yapısı. Yüksek Lisans Tezi, Marmara 
Üniversitesi Fen Bilimleri Enstitüsü. İstanbul, Türkiye, 54s.

Bozaoğlu, A.S. \& Akkuş, M. (2019). Nazik Gölü balıkçılığ1 üzerine bir araştırma. Journal of Anatolian Environmental and Animal Sciences, 4(3), 380-386. DOI: 10.35229/jaes.605597

Bozaoğlu, A.S. \& Yeşil, A. (2019). The socio economic structure of Lake Van. Fresenius Enviromental Bulletin, 28(10), 7206-7211.

Cilbiz, M., Hanol, Z., Cilbiz, N., Şınar, Ş. \& Savaşer, S. (2014). Multifilament gillnet and trammel net selectivity for the silver crucian carp (Carassius gibelio Bloch, 1782) in Eğirdir Lake, Isparta, Turkey. Turkish Journal of Fisheries and Aquatic Sciences, 14(4), 905-913.

Cilbiz, M., Küçükkara, R., Ceylan, M., Savaşer, S. \& Meke, T. (2015). Trammel net selectivity of common carp (Cyprinus carpio L., 1758) in Manyas Lake, Turkey. Journal of Limnology and Freshwater Fisheries Research, 1(1), 1-7. DOI: 10.17216/LimnoFish-5000083989

Çınar, Ş. (2010). Eğirdir Gölü'nde monofilament (tek kat) ve multiflament (çok kat) fanyal ăgların av verimliliklerinin karşılaştırılması. Yüksek Lisans Tezi, Süleyman Demirel Üniversitesi Fen Bilimleri Enstitüsü. Isparta, Türkiye, 50s.

Dartay, M. \& Canpolat, İ. (2017). Keban Baraj Gölü (Elazığ/Türkiye) su ürünleri kooperatiflerine ortak balıkçıların sosyo-ekonomik yapısı. Ege Journal of Fisheries and Aquatic Sciences, 34(1), 41-46. DOI: 10.12714/egejfas.2017.34.1.06

Dartay, M., Duman, E. \& Ateşşahin, T. (2010). Keban Baraj Gölü Pertek Bölgesi uzatma ağları balıkçılığı ve av verimi. Journal of Fisheries Sciences.com, 4(4), 384-390. DOI: 10.3153/jfscom.2010041

Dartay, M., Duman, E., Duman, M. \& Ateşşahin, T. (2009). The socio-economic analysis of fishermen Pertek region in Keban Dam Lake. Ege Journal of Fisheries and Aquatic Sciences, 26(2), 135-138.

Demirol, F. \& Yüksel, F. (2013). Keban Baraj Gölü kerevit avcılığının sosyo-ekonomik yapısı. Bilim ve Gençlik Dergisi, 1(2), 13-23.

Dereli, H., Kebapçıŏlu, T., Şen, Y., Ölçek S.Z. \& Özdemir, M. (2018). Demirköprü Baraj Gölü (Manisa, Türkiye) balıkçılığı: av araçları ve ticari türler. Limnofish-Journal of Limnology and Freshwater Fisheries Research, 4(3), 154-168. DOI: 10.17216/limnofish.439029

Doğan, K. (2009). İznik Gölü (Bursa) gümüș balığı avcılığı yapan tekne sahibi balıç̧ıların sosyo ekonomik analizi. Journal of FisheriesSciences.com, 3(1), 58-67.
Doğan, K. \& Gönülal, O. (2011). Fisheries of Gökçeada Island (Aegean Sea) and socio- economic structure of fishermen. The Black Sea Journal of Science, 2(5), 57-69.

Duman, E. \& Çelik, A. (2001). Atatürk Baraj Gölü Bozova Bölgesi'nde avlanan balıklar ve verimlilikleri. Ege Journal of Fisheries and Aquatic Sciences, 18(1-2), 65-69.

Ergüden, D., Ergüden, S. \& Öztekin, R. (2007). Seyhan Baraj Gölü (Adana) balıkçı profili durumu. Ulusal Su Günleri, 3(1), 5-6.

Güngör, G., Özen, S.Ş. \& Güngör, H. (2007). The socioeconomic structure of fishery activities and seafood marketing in Marmara Sea: a case study along the coastal area of Tekirdag province. Journal of Tekirdag Agricultural Faculty, 4(3), 311-325. DOI: 10.17216/LimnoFish-5000083989

Karabulut, K. (2018). A $\breve{g r}$ ilinin sosyo-ekonomik profili, 1. Baskı, AİÇÜ Yayınları, Ankara, Türkiye, 421p.

Karadal, E. (2014). Akdeniz Bölgesi (Türkiye) sahil şeridi deniz balıkçılı̆̆ının sosyo- ekonomik durumu. Doktora Tezi, Ordu Üniversitesi Fen Bilimleri Enstitüsü, Ordu, Türkiye, $77 \mathrm{~s}$.

Karakuş, Y. (2015). Avrupa Birliği’nde küçük ölçekli balıkçılı̆̆ın sosyo-ekonomik durumu, yönetimi ve Türkiye ile karşılaştırılması, AB Uzmanlık Tezi, Gıda, Tarım ve Hayvancılık Bakanlığı, Ankara, Türkiye.

Kolding, J. \& van Zwieten, P. (2014). Sustainable fishing of inland waters. Journal of Limnology. 73(1), 128-144. DOI: 10.4081/jlimnol.2014.818

Korkut, S.O., Saygı, H. \& Cesur, M. (2015). Socioeconomic structure of the fishermen on Lake Beysehir. Türk Tarım ve Doğa Bilimleri Dergisi, 2(2), 157-162.

Mete, O.S. \& Yüksel, F. (2014). Seyhan Baraj Gölü’ndeki ticari ve sportif balıkçılığın sosyo-ekonomik analizi. Bilim ve Gençlik Dergisi, 2(1), 27-42.

Mutlu, C., Uncumusaoğlu, C.M. \& Verep, B. (2018a). The Socio-Economic Structure Of Giresun Fishermen. Fresenius Environmental Bulletin, 27(8), 5531-5539.

Mutlu, C., Uncumusaoğlu, C.M. \& Verep, B. (2018b). Giresun İlindeki Balık Avlama Filosunun Teknik özellikleri. Journal of Anatolian Environmental and Animal Sciences, 3(2), 68-76.

Özbilgin, Y., Gökçe, G., Özbilgin, H., Çelik, O., Ünal, V. \& Tokaç, A. (2009). Kuzeydoğu Akdeniz balıkçılığının yapısal analizi (Rapor No. BAPSÜF AGT (YÖ) 2007-1), Mersin, Türkiye, Mersin Üniversitesi Bilimsel Araştırma Projeleri, 340 . 
Özer, A., Soylu, M. \& Uzmanoğlu, S. (2010). Uluabat (Apolyont) Gölü kadın balıkçılarının profili. İstanbul Üniversitesi Su Ürünleri Dergisi, 25(2), 11-24.

Öztürk, O. (2014). A ̆grr ili Balık Gölü’nde yaşayan balıkların tür tespitinin yapılması ve türlerin bazı biyolojik özelliklerinin araştırlması. Yüksek Lisans Tezi, Balıkesir Üniversitesi, Balıkesir Üniversitesi Fen Bilimleri Enstitüsü. Balıkesir, Türkiye, $115 \mathrm{~s}$.

Reis, İ., Cerim, H. \& Ateş, C. (2020). Aşağı Sakarya Nehri balıkçılarının sosyo-ekonomik analizi. Aquatic Research, 3(2), 66-71. DOI: 10.3153/AR20006

Sağlam, N. \& Karadal, E. (2016). Akdeniz Bölgesi sahil şeridi deniz balıkçılığının sosyo- ekonomik yapısı. Süleyman Demirel Üniversitesi Ĕ̈irdir Su Ürünleri Fakültesi Dergisi. 12(2), 158-169. DOI: 10.22392/egirdir.285172

Şahinler, S., Can, M.F., Görgülü, Ö. \& İğne, K.D. (2005). Samandağ ilçesinde (Hatay) balıkçılığın genel durumu, sorunları ve çözüm önerileri üzerine bir araştırma, Firat Üniversitesi Fen ve Mühendislik Bilimleri Dergisi, 17(4), 605-615.

Şen, Y. (2016). Demirköprü Baraj Gölü'nde sazan (Cyprinus carpio L., 1758) türü için kullanılan uzatma ağlarının av verimliliği ve seçiciliğinin belirlenmesi. Yüksek Lisans Tezi, İzmir Katip Çelebi Üniversitesi, Fen Bilimleri Enstitüsü. İzmir, Türkiye. $79 \mathrm{~s}$.

Tokaç, A., Ünal, V., Tosunoğlu, Z., Akyol, O., Özbilgin, H. \& Gökçe, G. (2007). Ege Denizi balıkçılığının yapisal analiz (Rapor No 2002/SÜF/006). İzmir, Türkiye, Ege Üniversitesi Bilimsel Araştırma Projeleri, 161s.

TÜİK. (2020). Türkiye İstatistik Kurumu. Alıntılanma adresi:

http://www.tuik.gov.tr/PreTablo.do?alt_id=1005 (05 Haziran 2020).

Uzmanoğlu, S. \& Soylu, M. (2012). Yeni Karpuzlu Baraj Gölü balıkçılarının sosyo-ekonomik yapısı. Su Ürünleri Dergisi, 29(4), 175-179.

Uzmanoğlu, S., Morkoyunlu Yüce, A., Bilgin, F. \& Soylu, M. (2013). Eğirdir Gölü balıkçı profili. Ĕ̈irdir Su Ürünleri Fakültesi Dergisi, 9(2), 8-13.

Ünal, V. (2003). Yarı zamanlı küçük ölçekli balıkçılığın sosyo ekonomik analizi, Foça (Ege Denizi). Ege Journal of Fisheries and Aquatic Sciences, 20(12), 165-172.

Yem, I.Y. (2014). Gillnet selectivity of Salmo trutta L. from two Lakes in Iceland as a reference for practical application on Lake Keinji fisheries. http://www.unuftp.is/static/fellows/document/inn 14prf.pdf. (10 Haziran 2019).

Yılmaz, E. \& Pulatsü, S. (2019). Isparta ve Manisa ili iç su avlak sahaları balıkçılarının sosyo- ekonomik yapıs1. Çanakkale Onsekiz Mart University Journal of Marine Sciences and Fisheries, 2(1), 90-101.

Yiğit, H., Soylu, M. \& Uzmanoglu, S. (2009). Sakarya ili göllerinin balıkçı profili. Journal of Fisheries and Aquatic Sciences, 24(2), 9-23.

Yücel, Ş. (2006). Middle Black Sea region fishing and socio-economic status of fishermen. Ege Journal of Fisheries and Aquatic Sciences, 23(1-3), 529532. 